\title{
Flexural Characteristics of RC Beams Retrofitted using FRP and Cement Matrix Composite
}

\author{
Abhishek Sharma ${ }^{1}$, Tara Sen ${ }^{2}$, Joyanta Pal ${ }^{3}$ \\ ${ }^{l}$ (Post graduate student/Department, of civil engineering/ NIT Agartala, India) \\ ${ }^{2,3}$ (Assistant professor/Department of civil engineering/ NIT Agartala, India)
}

\begin{abstract}
In this study flexural strength of beams retrofitted using cement matrix composite and conventional epoxy binder are compared. The matrix is made using cement, fly ash, admixtures and fibres. For this study, ten beams of cross section $100 \times 135 \mathrm{~mm}$ and overall length of $1 \mathrm{~m}$ are casted. Two of the beams served as control beams. The other eight beams are strengthened using EB technique. Group 1 having 2 beams strengthened with glass fibers and other 2 beams with sisal fibers using cement matrix composite. Group 2, having 2 beams strengthened with glass fibers and 2 beams with sisal fibers using sikadur lp 32 epoxy binder. Both the fibers are applied in the flexure zone in both above describe groups. Results are compared between retrofitted beams using cement matrix composite and conventional artificial binder which shows cement matrix composite is an effective alternate of the epoxy binder.
\end{abstract}

Keywords - Cement matrix composite, EB technique, Flexural strengthening, Glass fiber, sisal fiber

\section{INTRODUCTION}

The deterioration of civil engineering structures takes place either due to poor maintenance, corrosion or impact of natural forces i.e., earthquake. Such deteriorated structures cannot take the load for which they had been designed. So, complete demolition of whole structure is not a wise choice as in the modern civil engineering there is plenty of options available to increase the strength of damaged structures without demolishing the whole structure. As over the years since the discovery of seismic forces there has been rigorous changing in the design codes because the magnitude of seismic forces are uncertain which always creates a vague idea of stability of the structure. Along with that, poor maintenance gradually decreases the strength of a structure as corrosion weakens the strength of fundamental part of RCC structures i.e., reinforcement and ageing decreases the strength of a structure. So it is not always possible to demolish the structure as it does not prove economic. For a solution of this retrofitting has been proposed.

Over the years several techniques of retrofitting have been used, one is concrete jacketing [1][2] which increases the strength but it takes space twice to the deteriorated structure and disturbs the aesthetic appearance of vicinity and other one is steel jacketing [3][4], which also increases the strength but embracement of steel jackets to the deteriorated structure is vulnerable to corrosion which in the future would demand another course of retrofitting. For durability fiber Reinforced Polymer (FRP) is adopted [5] which consists of fiber which act as reinforcement embedded in thermosetting matrix. It is available in many forms such as sheets, plates and bars. But mostly FRP sheets are preferable over plates and bars, as sheets possess high flexibility and easiness along with that it can be done in both zones i.e. flexure and shear. This study shows the effect on flexural strength on beams after being retrofitted by the epoxy and FRP and results are shown by using graphs and tables. 10 beams of cross-section 100x135 of grade M25 are designed out of which 4 are plastered with epoxy in flexure zone which acts as an adhesive medium for glass fiber and sisal fiber sheet [6-8]. The next set of 4 beams are designed with same cross-section and grade but different adhesive medium i.e., cementitious matrix [9-12] and in this set strength is directed by glass and sisal fibers rather than glass and sisal sheets of them and remaining 2 beams are served as control beams as given in Table 1 which shows the beams description.

Table I. Beam description

\begin{tabular}{|l|l|}
\hline Names & Beam description \\
\hline C1,C2 & Control beams \\
\hline SC1,SC2 & Beams retrofitted with sisal fibre using cementitious matrix \\
\hline
\end{tabular}




\begin{tabular}{|l|l|}
\hline SE1,SE2 & Beams retrofitted with sisal fibre sheets and epoxy \\
\hline GC1,GC2 & Beams retrofitted with glass fibre using cementitious matrix \\
\hline GE1,GE2 & Beams retrofitted with glass fibre sheets and epoxy \\
\hline
\end{tabular}

\section{MATERIALS}

Cement: OPC 43 grade cement is used satisfying the requirement of IS 8112 . Specific gravity is obtained and having initial and final setting time 30 minutes and 600 minutes respectively.

Aggregates: Crushed angular coarse aggregate of $10 \mathrm{~mm}$ nominal size is used and locally available sand of zone 4 is used satisfying IS 383 provisions.

Reinforcement: HYSD 500 steel bars of $8 \mathrm{~mm}$ and $6 \mathrm{~mm}$ are used in the design of beams. $8 \mathrm{~mm}$ bars are used as longitudinal bars for both compression and tension side while $6 \mathrm{~mm}$ are used as shear stirrups.

Water: Clean water free from impurities such as salts and chlorides is used. It helps in providing strength to the cement gel. Quality of water affects the strength of concrete.

Fibres: Fibre sheets are used with epoxy binder and fibre pieces are used in cementitious matrix. Fig. 1 shows two types of fibres used in this study. Glass fibre which possess high tensile strength but with relatively low modulus of elasticity. GFRP sheets is most commonly used in externally bonded FRP system. Sisal fibres are natural fibre obtained from agave sisalana which is a native of Mexico.

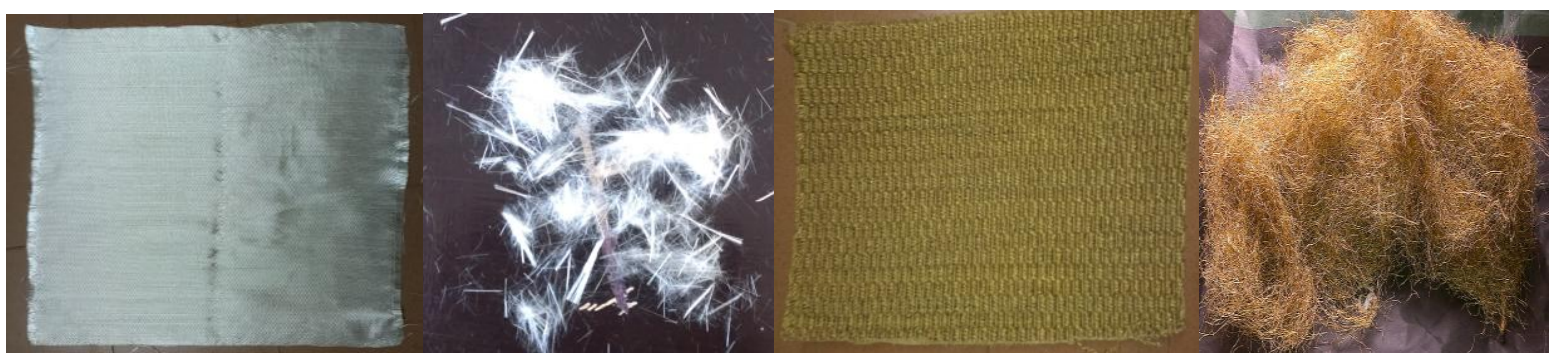

(a)

(b)

(c)

(d)

Fig. 1: (a) Glass sheet and (b) Glass fibre (c) sisal sheet (d) sisal fibre

\section{Adhesive}

Epoxy: Epoxy resin is one the types of adhesives which is used to stick fibre to concrete surface. Sikadur-32 lp epoxy resin is used in the experiment. In has two components, component A as resin and component B as hardener which have to be mixed thoroughly in the ratio 2:1 by weight. After having a uniform greyish colour, apply the matrix using brush on the chiselled contact surface. Fibres sheets has been cut in $300 \mathrm{~mm} \times 100 \mathrm{~mm}$ dimensions and applied on the matrix already present on the surface of beams.

Cementitious matrix: Cement matrix composite is prepared using cement, silica fumes, super plasticizer water and fiber (glass/sisal). Silica fumes is used by $10 \%$ of weight of the cement. Super plasticizer is added by $2 \%$ of the weight of cement used. Fibers are cut in $3-4 \mathrm{~cm}$ length and mixed in the matrix uniformly.

\section{EXPERIMENTAL PROGRAM}

To cast the beams of 100x135 mm dimension rectangular wooden moulds are prepared. With concrete of grade M-25 and reinforcement of HYSD 500 steel bars, 10 beams of dimension $100 \times 135 \mathrm{~mm}$ and a span of $1000 \mathrm{~mm}$ 
are casted. As shown in figure 2 all the beams are reinforced with 2 bars of $8 \mathrm{~mm}$ in the tension (bottom) zone and 2 bars in the compression (top) zone. $8 \mathrm{~mm}$ bars are used as longitudinal bars for both compression and tension side while $6 \mathrm{~mm}$ are used as shear stirrups. Shear reinforcement is provided @90mm c/c. Additional shear stirrups are provided to make sure the beam fails in flexure only. All these beams have been cured for 28 days.
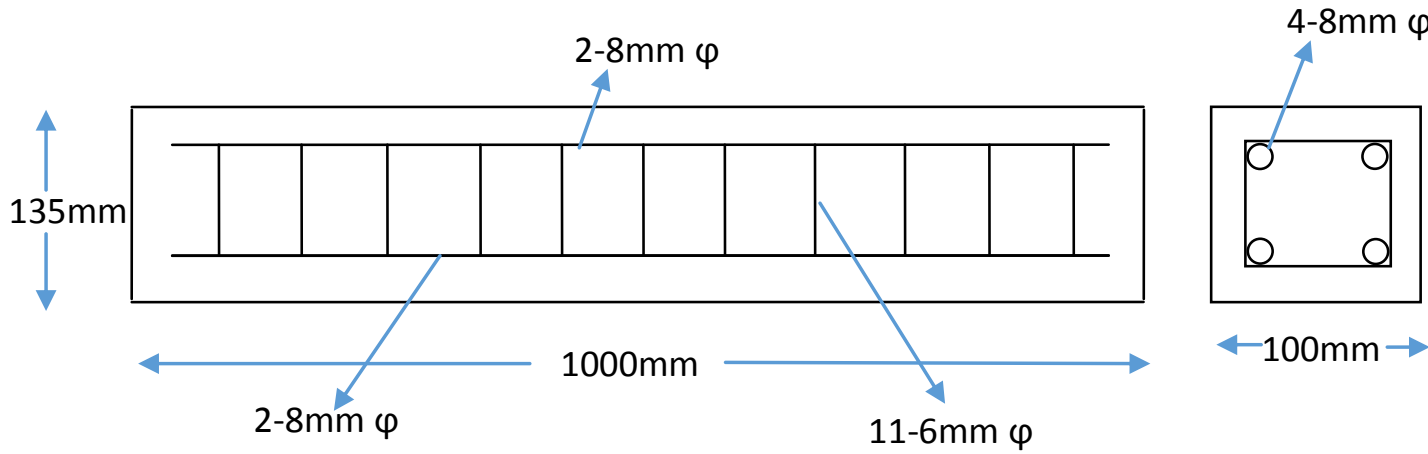

Fig. 2 Reinforcement Detailing

\section{APPLICATION OF FIBRES}

Strengthening of beams is done in two groups in the flexure zone after 28 days of the curing. The beams surface is made rough to remove dirt and to promote good bonding with the fiber. In group 1 two beams are retrofitted with glass fiber and another two beams are retrofitted with sisal fiber using cementitious matrix as shown in fig. 3

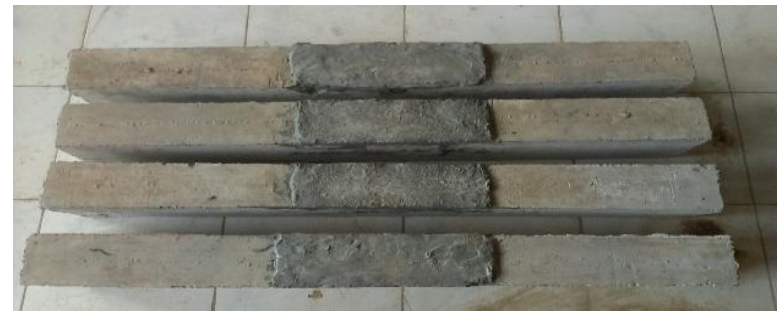

Fig. 3 Beams retrofitted using cement matrix composite

As fig 4, shows, in the other group 2 two beams are retrofitted with glass fiber sheets and remaining two beams with sisal fiber sheets using epoxy binder. Curing is done after strengthening of the beams before testing.

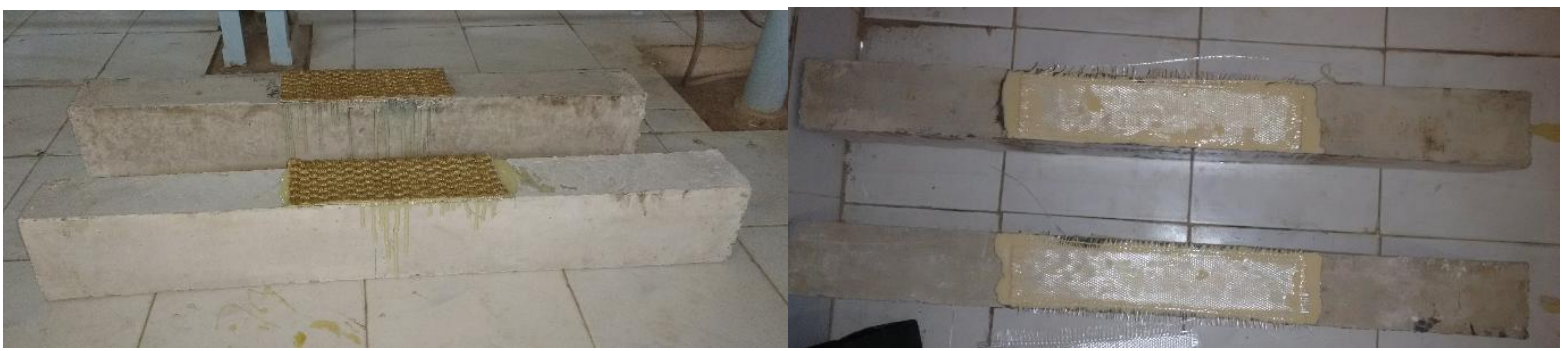

Fig. 4 Beams Retrofitted Using Sisal and Glass Fiber Sheets with Epoxy Binder

\section{TEST SETUP}

Experimental investigations are carried out on beam specimens to determine the flexural capacity under two point load and simply supported end conditions. The controlled and retrofitted beam specimens are tested under 
two point loads on the loading frame as shown in fig. 5. The load has been applied through $450 \mathrm{KN}$ load cell, with simple supports placed at $50 \mathrm{~mm}$ from ends. The load is then applied gradually at a constant rate and load versus deflection values are recorded at an interval of $5 \mathrm{KN}$.

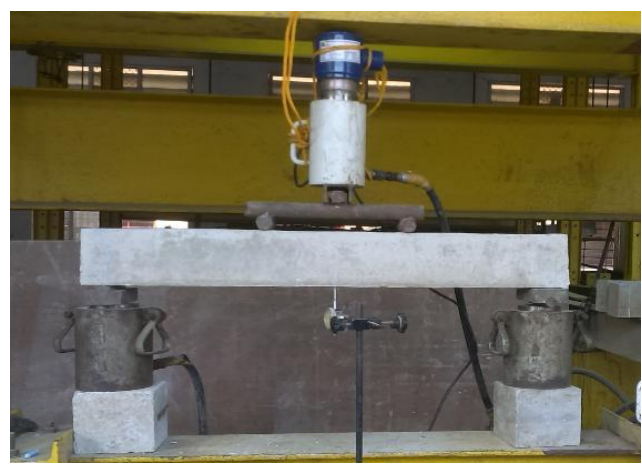

Fig. 5 Test setup

\section{RESULTS AND DISCUSSIONS}

The ultimate load and averages of the ultimate loads of the beams of all groups tested in this series are shown in Table 2. load deflection relationship is also plotted for all the groups. Load versus mid point deflection plots from the experimental results are also presented.

Table II Beam Results

\begin{tabular}{|c|c|c|c|}
\hline Beam description & Ultimate load $(\mathrm{KN})$ & $\begin{array}{l}\text { Average ultimate load } \\
(\mathrm{KN})\end{array}$ & $\begin{array}{l}\text { Percentage increase in the } \\
\text { ultimate load carrying capacity }\end{array}$ \\
\hline $\mathrm{C} 1$ & 45 & \multirow[t]{2}{*}{46.5} & \multirow[t]{2}{*}{-} \\
\hline $\mathrm{C} 2$ & 48 & & \\
\hline SC1 & 51 & \multirow[t]{2}{*}{52} & \multirow[t]{2}{*}{$11.8 \%$} \\
\hline $\mathrm{SC} 2$ & 53 & & \\
\hline SE1 & 54 & \multirow[t]{2}{*}{54.5} & \multirow[t]{2}{*}{$17.2 \%$} \\
\hline SE2 & 55 & & \\
\hline GC1 & 56 & \multirow[t]{2}{*}{56.5} & \multirow[t]{2}{*}{$21.5 \%$} \\
\hline GC2 & 57 & & \\
\hline GE1 & 59 & \multirow[t]{2}{*}{60} & \multirow[t]{2}{*}{$29.03 \%$} \\
\hline GE2 & 61 & & \\
\hline
\end{tabular}

The averages of the ultimate loads of the beams of all groups tested in this series are shown in Fig. 6

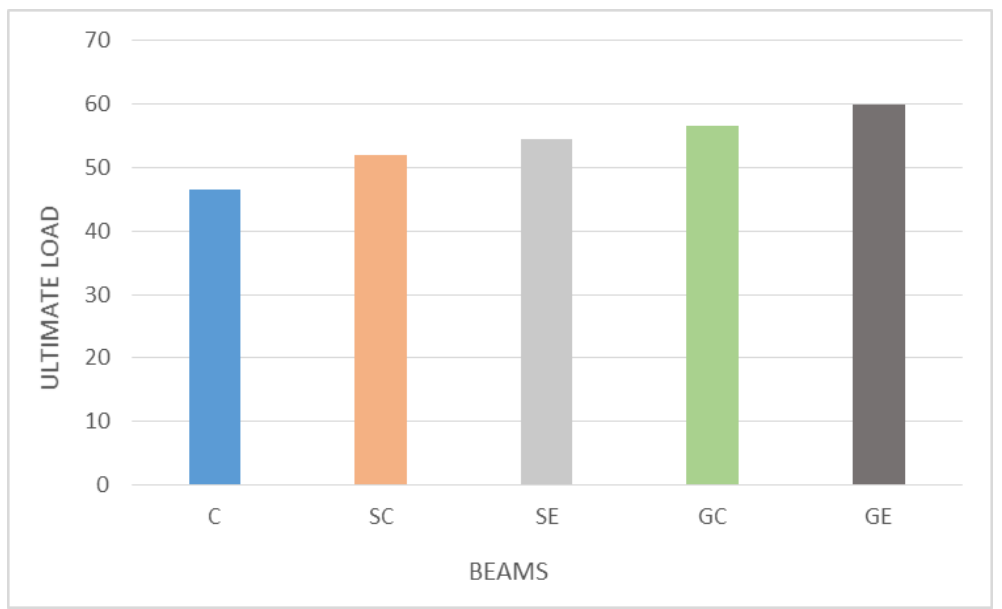

Fig.6:Average Ultimate Loads For All the Beams 
Load deflection relationship is plotted for all the groups. As presented in Fig. 7 and Fig. 8 the behaviour of beam retrofitted using cement matrix composite with sisal and glass fibre is significantly changed.

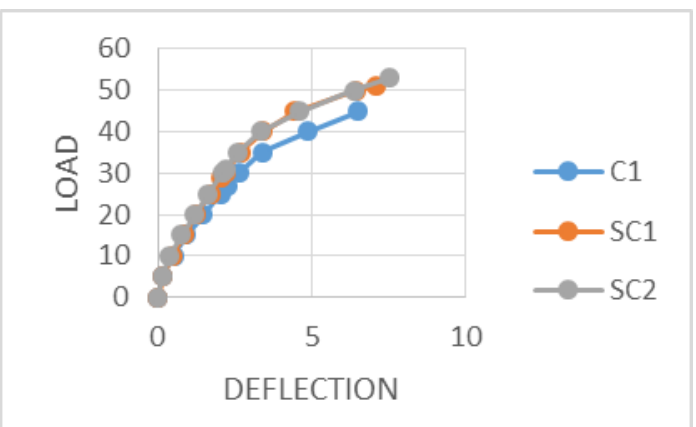

Fig. 7: Load deflection curve of control beam and retrofitted beam using sisal cementitious matrix

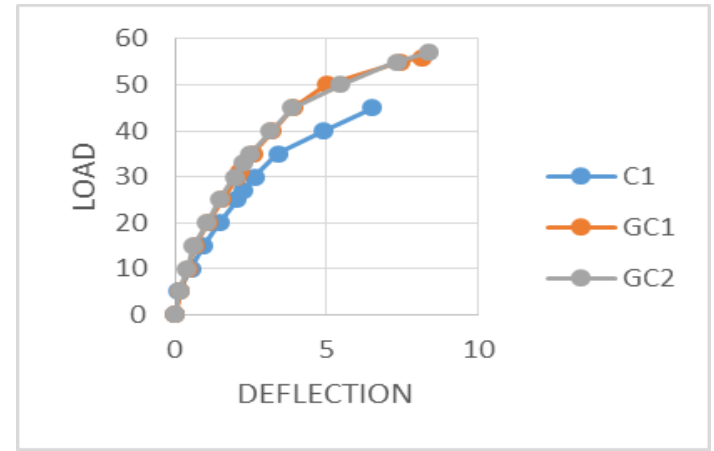

Fig. 8: Load deflection curve of control beam and retrofitted beam using sisal sheet with epoxy

Fig. 9 and Fig. 10 shows the load versus mid point deflection plots from experimental results. Beams retrofitted using GFRP and sisal fibre with epoxy binder also showing the increased strength.

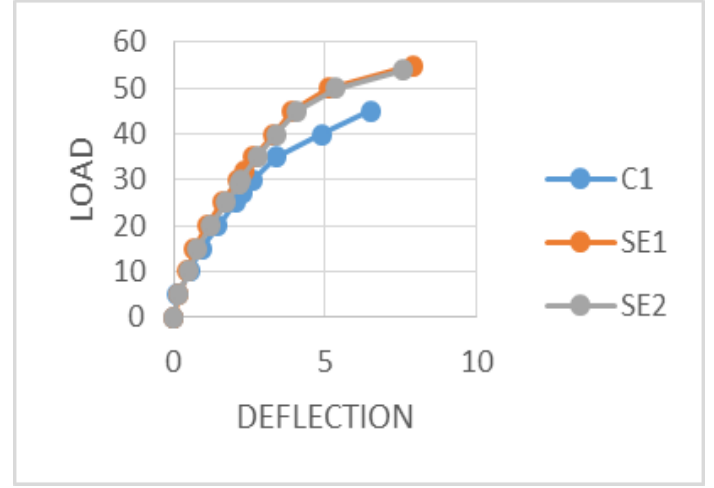

Fig.9: Load deflection curve of control beam and retrofitted beam using glass fibre cementitious matrix

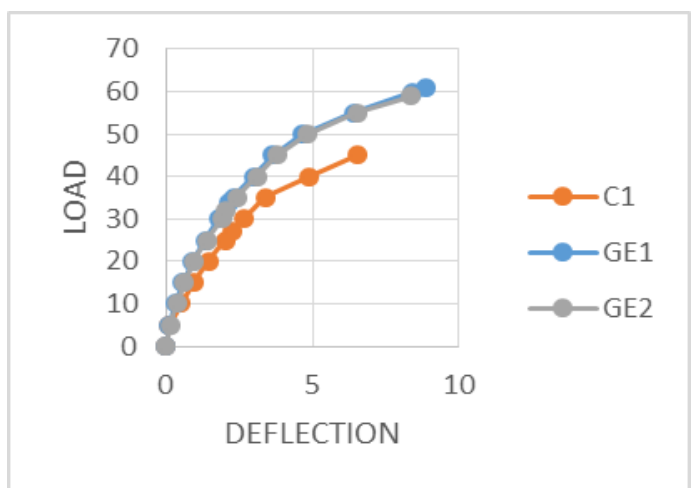

Fig. 10: Load deflection curve of control beam and retrofitted beam using glass fibre sheet with epoxy

Fig. 11 shows load deflection curve for retrofitted beams with sisal fibre using cementitious and epoxy binder and Fig 12. Shows the curve between retfitted beams with glass fibre using cementitious and epoxy binder

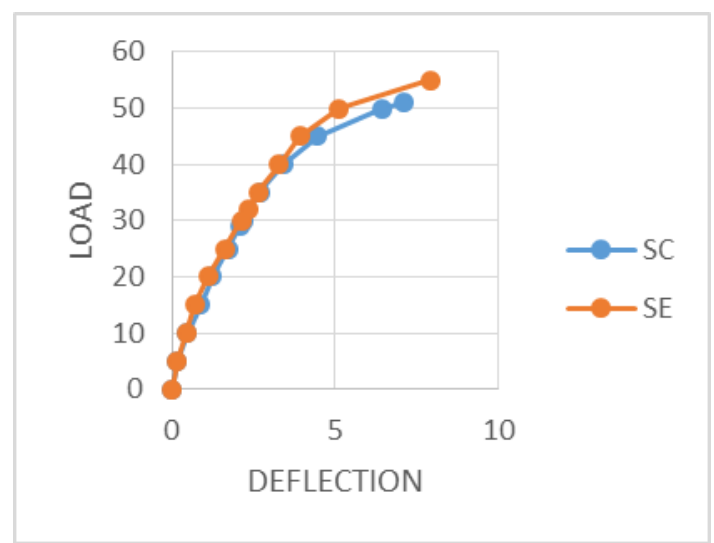

Fig.11:Load deflection curve of retrofitted beams with sisal fibre using cementitious and epoxy binder

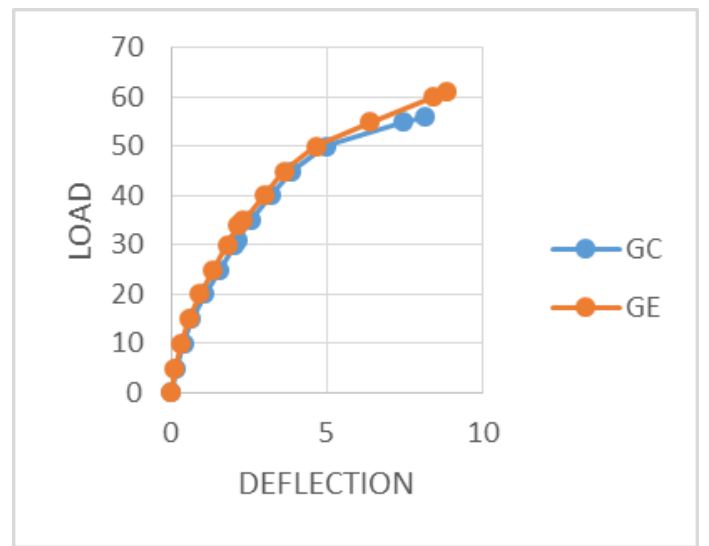

Fig.12: Load deflection curve of retrofitted beams with glass fibre using cementitious matrix and epoxy 


\section{CONCLUSION}

From the results the following conclusions are obtained

- The retrofitted beams with sisal fiber using cementitious matrix and using epoxy as binder have $11.8 \%$ and $17.2 \%$ more strength respectively than the control beams.

- The retrofitted beams with glass fiber using cementitious matrix and using epoxy have $21.5 \%$ and $29.03 \%$ more strength respectively than the control beams.

- Beams retrofitted with sisal fiber sheets using epoxy have $4.8 \%$ more strength than the beams retrofitted using cement matrix composite using sisal fiber.

- Beams retrofitted with glass fiber sheets using epoxy have $6.19 \%$ more strength than the beams retrofitted using cement matrix composite using glass fiber.

- Cement matrix composites does not emits toxic fumes like epoxy.

- Cement matrix composites have better thermal compatibility with concrete than epoxy in retrofitted beams.

- Cement matrix composites are economical and friendly to the construction industry and hence can be used as alternative of conventional epoxy binders.

\section{REFERENCES}

[1] V.C. Marlapalle, P.J. Salunke, and N.G. Gore, "Analysis \& Design of R.C.C. Jacketing for Buildings", International Journal of Recent Technology and Engineering (IJRTE), Volume 3 Issue 3, pp. 62-63, July 2014.

[2] Y.A. Hassanean, K.A. Assaf, S.E. Raheem, and A.N.M. Arafa, "Flexural behavior of strengthened and repaired R.C. beams by using steel fiber concrete jacket under repeated load", International Journal of Civil And Structural Engineering, Volume 3 No 3 , pp. 564-578, March 2013

[3] M.F. Belal, H.M. Mohamed, and S.A. Morad, "Behavior of reinforced concrete columns strengthened by steel jacket", HBRC Journal, Volume 11 Issue 2, pp. 201-212, August 2015.

[4] P. Nagaprasad, D.R. Sahoo and D.C. Rai, "Seismic strengthening of RC columns using external steel cage", Earthquake Engineering and Structural Dynamics, Volume 38, pp. 1563-1586, April 2009.

[5] T. Sen, and A. Paul, "Confining concrete with sisal and jute FRP as alternatives for CFRP and GFRP", International Journal of Sustainable Built Environment, Volume 4 Issue 2, pp. 248-264, April 2015.

[6] V.P.V Ramana, T. Kanta, and S.E Morton, "Behaviour of CFRPC Strengthened Reinforced Concrete Beams with Varying Degrees of Strengthening", Composites Part-B, ELSEVIER, Volume 31, pp. 461-470, 2000.

[7] S.P. Chiew, Q. Sun, and Y. Yu, "Flexural Strength of RC Beams with GFRP Laminates", Journal of composites for Construction ASCE, Volume 11 Issue 5, pp. 497-506, October 2007

[8] G. Murali, and N. Pannirselvam, "Flexural strengthening of reinforced concrete beams using Fibre Reinforced Polymer laminate", ARPN Journal of Engineering and Applied Sciences, Volume 6 Issue 11, pp. 41-47, 2011.

[9] A. Ambrisi and F. Focacci, "Flexural strengthening of RC beams with cement based composites", Journal of Composites for construction ASCE, Volume 15 Issue 5, pp. 707-720, September/October 2011.

[10] H. Shoukry, M.F. Kotkata, S. Enein, and M. Morsy, "Flexural Strength and Physical Properties of Fibre Reinforced Nano Metakaolin Cementitious Surface Compound", Construction and Building Materials, Volume 43, pp. 453-460, 2013.

[11] S. Babaeidarabad, G. Loreto, and A. Nanni, "Flexural strengthening of RC beams with an externally bonded fabric-reinforced cementitious matrix", Journal of Composites for construction ASCE, Volume 18, pp. 1-12, 2014.

[12] J.G Dai, B. Wang, and S.L. Xu, "Textile reinforced engineered cementitious composites (TR-ECC) overlays for the strengthening of RC beams", International Institute for FRP in construction for Asia-Pacific Region, Volume 9 Issue 11, pp. 7580, December 2009 